\title{
IFEATURE
}

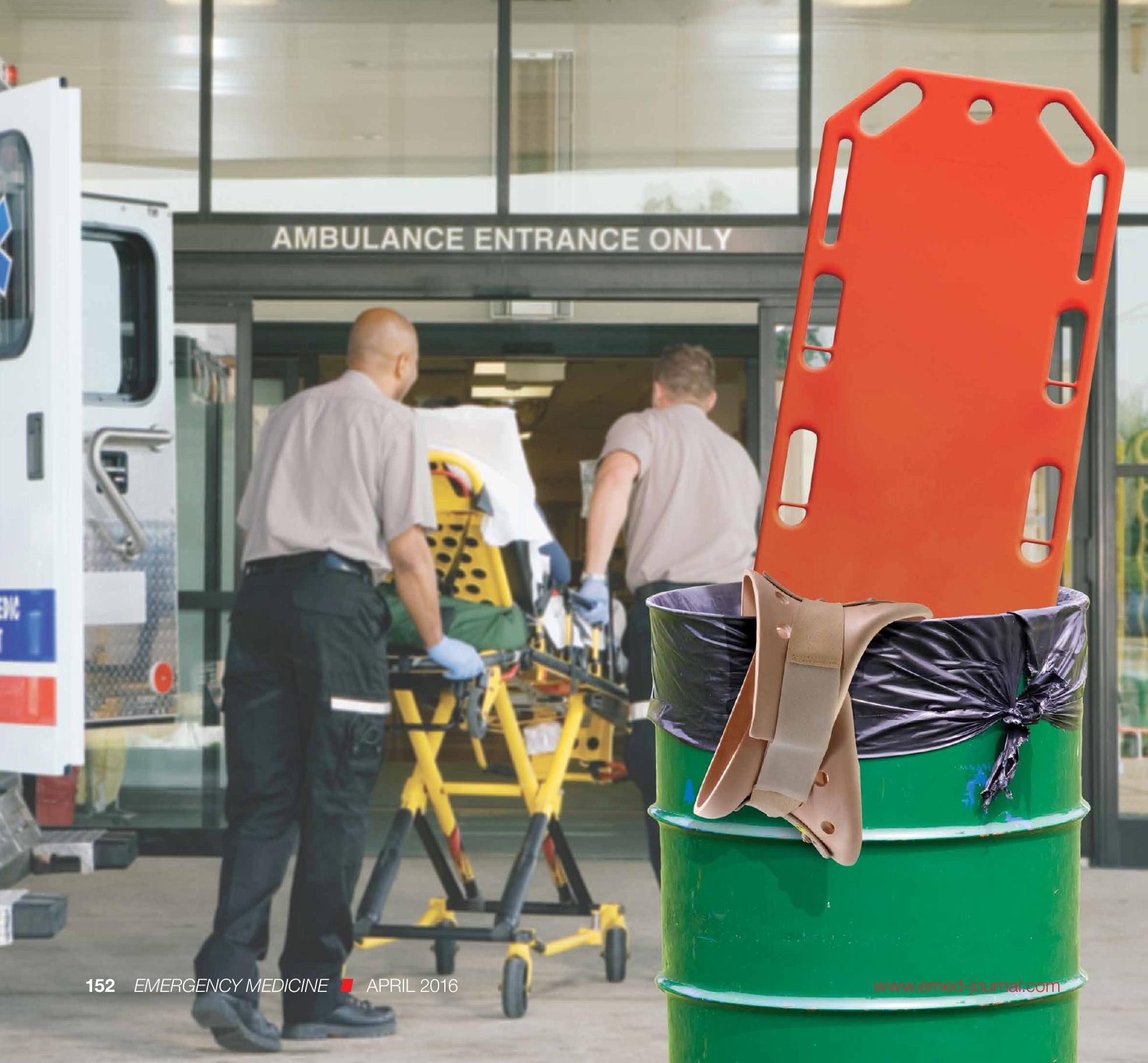




\section{The Changing Standard of Care for Spinal Immobilization}

James R. Myer, MD; Debra G. Perina, MD

\section{New guidelines suggest a more limited role for prehospital spinal immobilization based on increasing evidence that the practice often is not only unnecessary, but possibly harmful.}

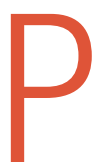

rehospital spinal immobilization has long been the standard of care (SOC) to prevent spinal cord injury in trauma patients, but utilizing the best data currently available, some professional societies recently released new recommendations that question this practice. Guidelines released in 2014 from the National Association of EMS Physicians (NAEMSP) and the American College of Surgeons Committee on Trauma (ACS-COT) support limited application of spinal immobilization. ${ }^{1}$ These guidelines note, "Given the rarity of unstable spinal injuries in EMS trauma patients, the number that might benefit from immobilization to prevent secondary injury is likely extremely small. For each patient who has potential benefit, hundreds to thousands of patients must undergo immobilization with no potential benefit." Further, they advise "utilization of backboards for spinal immobilization during transport should be judicious, so that potential benefits outweigh risks." Spinal immobilization should not be used at all in patients with penetrating trauma who do not present with obvious neurological injury and should be selective, based on objective findings of injury or the high potential for same. ${ }^{1}$

\section{Questioning a Long-standing Practice}

Fear of the consequences of spinal cord injury from significant vertebral fractures has dictated prehospital spinal immobilization to manage injured trauma patients for decades. For almost 50 years, it has been the SOC. However, increasing evidence that spinal immobilization is not only unnecessary, but may even cause harm has resulted in questioning this paradigm, which has lead to promoting a change in the SOC.

Spinal immobilization dates back to the mid-1960s, when Geisler et al $^{2}$ reported on a cohort of patients who suffered long-term paralysis from what was believed to be improper handling and failure to discover spinal injuries. Soon after, Farrington ${ }^{3,4}$ developed and published a systematic approach to spinal immobilization during extrication following blunt force trauma, supporting the widespread acceptance of backboards and cervical collars to immobilize the spine in injured trauma patients. Logic dictated that an unstable spine fracture could be worsened, or a cord injury could result, by unnecessary movement during extrication, transport, and initial evaluation in the ED, resulting in avoidable 
injury. This fear of potential secondary injury grew as more papers were published examining the link between prehospital handling of blunt force trauma patients and delayed paralysis. This resulted in the use of spinal immobilization on the majority of trauma patients, regardless of mechanism of injury or presenting symptoms. ${ }^{5,6}$

One review estimated that over $50 \%$ of trauma patients with no complaint of neck or back pain were transported with full spinal immobilization. ${ }^{7}$ This immobilization on uncomfortable long backboards typically continued in the ED for prolonged periods, until the spine could be cleared by physical examination and/or imaging studies. Yet a 2001 Cochrane review found that despite increasing use of spinal immobilization, no prospective, randomized controlled trial of the appropriate use of spinal immobilization or patient outcomes had ever been conducted. ${ }^{8}$

\section{What the Evidence Says}

How much evidence exists that supports the benefits of spinal immobilization? Not much. Studies on healthy volunteers and cadavers evaluating spinal motion with immobilization have been contradictory. ${ }^{9}$ One study found there was less motion with a cervical collar in place than without, ${ }^{10}$ whereas others found that the use of a cervical collar did not effectively reduce motion in an unstable spine..$^{11,12}$ Perry et $\mathrm{al}^{13}$ studied the effectiveness of different head immobilization techniques and found that none could eliminate head and neck motion during emergency medical services (EMS) transport. Still other reports, including two biomechanical studies, demonstrated increased neck motion when using conventional extrication techniques (cervical collar with backboard) versus controlled self-extrication with cervical collar only. ${ }^{14,15}$

\section{An Abundance of Literature on the Risks}

Whereas data regarding the actual benefits of spinal immobilization is lacking, an abundance of literature details the risks. One of the most frequently cited studies is also one of the most controversial. Hauswald et $\mathrm{al}^{16}$ compared the outcomes of two groups of patients with blunt force trauma who were either immobilized during transport (in New Mexico) or non-immobilized (in Malaysia) and found that the risk of disability was higher in the immobilized group (odds ratio, 2.03). Although these environments are very different, the authors noted that mechanism of injury, resources, and the size of the hospitals were similar. ${ }^{16}$

Studies of spinal immobilization in patients with penetrating trauma report even worse outcomes. In separate studies, Haut et $\mathrm{al}^{17}$ and Vanderlan et $\mathrm{al}^{18}$ demonstrated increased mortality when immobilization led to increased transport times and interference with other resuscitative measures. These and other studies have led the American College ofEmergency Physicians, NAEMSP, ACS-COT, the Prehospital Trauma Life Support Executive Committee, and other national organizations to recommend no spinal immobilization in patients with penetrating neck trauma. ${ }^{1,19,20}$

Many trauma patients arrive with complaints of pain at one or more sites. Some of these complaints, particularly back pain, may be secondary to the use of the backboard itself, especially in cases of prolonged transport. ${ }^{21,22}$ In a study of healthy volunteers who were immobilized on a backboard for 30 minutes, all of them reported pain, along with headaches, most often involving the occipital and sacral regions. ${ }^{23}$ A 1996 study compared spinal immobilization utilizing a backboard versus a vacuum mattress in 37 healthy volunteers with no history of back pain or spinal disease.$^{24}$ Compared to those immobilized with the vacuum mattress, patients immobilized with a backboard for 30 minutes were 3.1 times more likely to have symptoms, 7.9 times more likely to complain of occipital pain, and 4.3 times more likely to have lumbosacral pain. ${ }^{24}$ 
Increased pain complaints in the setting of trauma can result in increased imaging, leading to increased costs and unnecessary radiation exposure. ${ }^{25}$ Prolonged backboard times can also result in sacral pressure ulcers. ${ }^{26} \mathrm{~A}$ recent study has shown that patients who undergo computed tomography (CT) scans with automatic tube current modulation (as most modern multidetector row CT systems utilize) while on a backboard may be exposed to a significant increase in radiation dose. ${ }^{27}$

Spinal immobilization has also been linked to respiratory compromise, particularly with the use of straps across the chest, even when not applied tightly. One study found worse lung function test results in healthy immobilized volunteers. ${ }^{28}$ Other studies have shown that older patients (even when healthy) and those with lung or chest injury have an even larger degree of restriction and respiratory compromise..$^{29,30}$

Risks from immobilization are not isolated to backboards. The use of cervical collars alone also carries potential risks. (See "What About Cervical Collars?"”,31-39)

\section{Risk of Secondary Neurological Deterioration Is Low}

Many EMS systems have already adopted the new standards calling for less use of spinal immobilization. Though the evidence is compelling, not all EMS systems have adopted these standards due to strongly rooted beliefs and fears of longterm patient disability and subsequent litigation. However, these fears do not appear justified.

A recent review by Oto et $\mathrm{a}^{40}$ found only 42 cases of early secondary neurological deterioration after blunt trauma in all of the indexed medical literature. They noted, "In twelve cases the authors did attribute deterioration to temporally associated precipitants, seven of which were possibly iatrogenic; these included removal of a cervical collar, placement of a halo device, patient agitation, performance of flexion/

\section{What About Cervical Collars?}

Decreased mouth opening while in a C-collar can lead to increased difficulty with airway management. ${ }^{31}$ In a 2007 update of its 2001 review of spinal immobilization, the Cochrane team stated, "Because airway obstruction is a major cause of preventable death in trauma patients, and spinal immobilization, particularly of the cervical spine, can contribute to airway compromise, the possibility that immobilization may increase mortality and morbidity cannot be excluded." ${ }^{8}$

Multiple studies have shown a positive correlation between cervical collar placement and increased intracranial pressure (ICP). Davies et $\mathrm{al}^{32}$ found a mean rise in ICP of $4.5 \mathrm{~mm} \mathrm{Hg}$ when a collar was placed. Similarly, a review comparing ICP of injury-matched patients with cervical collars in place versus those without collars found a nearly $36 \%$ increase in the risk of increased ICP among those with cervical collars. ${ }^{33}$ In a prospective study, researchers measured ICP before and after cervical collar placement in head injured patients with a Glasgow Coma Scale (GCS) score $\leq 9$ and found a statistically significant increase in ICP with the collar in place. ${ }^{34}$

Although the mechanism for this increase in ICP is unclear, it may be due to venous congestion in the neck. ${ }^{35}$ Since head trauma with traumatic brain injury (TBI) is a common finding in blunt-force injury, any potential rise in ICP has the potential to worsen an already significant injury. Avoiding or reducing an increase in ICP is a fundamental principle in the management of TBI.

Cervical collars may worsen existing spinal injury in certain situations. A cadaver study revealed a $7.3 \mathrm{~mm}$ separation of $\mathrm{C} 1$ and $\mathrm{C} 2$ when a cervical collar was applied after researchers cut the anterior-posterior ligamentous support to simulate ligament injury. ${ }^{36}$ This possibility is of even greater concern in patients with predisposing conditions, such as ankylosing spondylitis, that can increase risk of spinal injury. Several case reports of exacerbated spinal injury in such patients when placed in cervical collars suggest that a vertebral injury without initial cord injury can result in a cord injury by forcing the neck into a cervical collar. ${ }^{37-39}$

extension films, 'unintentional manipulation,' falling in or near the ED, and forced collar application in patients with ankylosing spondylitis.” Thirteen of these cases occurred during prehospital care, none of them sudden and movement-provoked, and all reported by a single study." This review highlights the rarity of secondary deterioration.

\section{When Should Immobilization Be Used?}

So what's the next step for spinal immobilization in the field? How do we appropriately protect trauma patients during transport? As always seems to be the case in medicine, more evidence is needed. Oteir 
et $\mathrm{al}^{41}$ recently published a review of new literature on the epidemiology and current practice of prehospital spine management. They reported that early (8-24 hours) transfer of patients with spinal injury to spinal care units, along with effective resuscitation, was the most important determinant of better neurological outcomes. ${ }^{41}$ This review reaffirms the need for more data evaluating the relationship between spinal immobilization and neurological outcomes.

Currently, recommendations call for selective spinal immobilization to decrease unnecessary application and potential harm. Use of backboards for spinal immobilization should be limited to the following types of patients: ${ }^{1,20}$

- Blunt trauma and altered level of consciousness;

- Spinal pain or tenderness;

- Neurological complaint (eg, numbness or motor weakness);

- Anatomic deformity of the spine;

- High-energy mechanism of injury and:

- Drug or alcohol intoxication;

- Inability to communicate; and/or

- Distracting injury.

Patients for whom immobilization on a backboard is not necessary include those with all of the following:

- Normal level of consciousness (GCS 15);

- No spine tenderness or anatomic abnormality;

- No neurological findings or complaints;

- No distracting injury;

- No intoxication.

Cervical collars alone are still recommended for use in patients who do not meet validated clinical rules, such as the NEXUS or Canadian C spine rules. . $^{1,20,42,43}$
As these rules are well validated, they can be safely used to determine who should have a cervical collar placed, with or without a backboard. In a retrospective review, selective spinal immobilization was found to be $99 \%$ sensitive in identifying patients with cervical injuries. ${ }^{44}$

Clearly, there is still work to be done. Due to the relative rarity of actual spinal cord injury with the consequences of neurological injury, prospective trials in this area are rare and very difficult to safely design. However, there is growing confidence that selective spinal protocols, together with the inclusion of validated clinical rules, can effectively limit exposure to unnecessary spinal immobilization. As the current evidence continues to mount for the potential harm in indiscriminate backboard and cervical collar use, it seems clear we should strive to decrease the overuse of prehospital and early spinal immobilization consistent with current position statements and validated clinical rules.

\section{References}

1. White CC, Domeier RM, Millin MG. EMS spinal precautions and the use of the long backboard - resource document to the position statement of the National Association of EMS Physicians and the American College of Surgeons Committee on Trauma. Prehosp Emerg Care. 2014;18(2):306-314.

2. Geisler WO, Wynne-Jones M, Jousse AT. Early management of patients with trauma to the spinal cord. Med Serv J Can. 1966;22(7):512-523.

3. Farrington JD. Death in a ditch. Bulletin of the American College of Surgeons. 1967;52(3):121-130.

4. Farrington JD. Extrication of victims- surgical principles. J Trauma. 1968;8(4):493-512.

5. Riggins RS, Kraus JF. The risk of neurologic damage with fractures of the vertebrae. J Trauma. 1977;17(2):126-133.

6. Soderstrom CA, Brumback RJ. Early care of the patient with cervical spine injury. Orthop Clin North Am. 1986;17(1):3-13.

7. McHugh TP, Taylor JP. Unnecessary out-of-hospital use of full spinal immobilization. Acad Emerg Med. 1998;5(3):278-280. 
8. Kwan I, Bunn F, Roberts I. Spinal immobilisation for trauma patients. Cochrane Database Syst Rev. 2001;(2):CD002803.

9. Sundstrøm T, Asbjørnsen H, Habiba S, Sunde GA, Wester K. Prehospital use of cervical collars in trauma patients: a critical review. J Neurotrauma. 2014;31(6):531-540.

10. Conrad BP, Rechtine G, Weight M, Clarke J, Horodyski M. Motion in the unstable cervical spine during hospital bed transfers. J Trauma. 2010;69,432-436.

11. Horodyski M, DiPaola CP, Conrad BP, Rechtine GR. Cervical collars are insufficient for immobilizing an unstable cervical spine injury. J Emerg Med. 2011;41(5):513-519.

12. Hughes SJ. How effective is the Newport/Aspen collar? A prospective radiographic evaluation in healthy adult volunteers. I Trauma. 1998;45(2):374-378.

13. Perry SD, McLellan B, McIlroy WE, Maki BE, Schwartz M, Fernie GR. The efficacy of head immobilization techniques during simulated vehicle motion. Spine (Phil Pa 1976). 1999;24(17):1839-1844

14. Engsberg JR, Standeven JW, Shurtleff TL, Eggars JL, Shafer JS, Naunheim RS. Cervical spine motion during extrication. J Emerg Med. 2013;44(1):122-127.

15. Dixon M, O’Halloran J, Cummins NM. Biomechanical analysis of spinal immobilization during prehospital extrication-a proof of concept study. Emerg Med J. 2014;31(9):745-749.

16. Hauswald M, Ong G, Tandberg D, Omar Z. Out-ofhospital spinal immobilization: its effect on neurologic injury. Acad Emerg Med. 1998;5(3):214-219.

17. Haut ER, Kalish BT, Efron DT, et al. Spine immobilization in penetrating trauma: more harm than good? J Trauma. 2010;68(1):115-120.

18. Vanderlan WB, Tew BE, McSwain NE. Increased risk of death with cervical spine immobilization in penetrating cervical trauma. Injury. 2009;40(8):880-883

19. Stuke LE, Pons PT, Guy JS, Chapleau WP, Butler FK, McSwain NE. Prehospital spine immobilization for penetrating trauma-review and recommendations from the Prehospital Trauma Life Support Executive Committee. J Trauma. 2011;71(3):763-769.

20. American College of Emergency Physicians. Policy Statement- EMS Management of Patients with Potential Spinal Injury. 2015. Available at: http://www. acep.org/Physician-Resources/Policies/Policy-Statements/EMS-Management-of-Patients-with-PotentialSpinal-Injury. Accessed February 9, 2016.

21. Barney RN, Cordell WH, Miller E. Pain associated with immobilization on rigid spine boards. Ann Emerg Med. 1989;18:918.

22. Cooney DR, Wallus H, Asaly M, Wojcik S. Backboard time for patients receiving spinal immobilization by emergency medical services. Int J Emerg Med. 2013;6(1):17.

23. Chan D, Goldberg R, Tascone A, Harmon S, Chan L. The effect of spinal immobilization on healthy volunteers. Ann Emerg Med. 1994;23(1):48-51.

24. Chan D, Goldberg RM, Mason J, Chan L. Backboard versus mattress splint immobilization: a comparison of symptoms generated. J Emerg Med, 1996;14(3):293-298.

25. March J, Ausband S, Brown L. Changes in physical examination caused by use of spinal immobilization. Prehosp Emerg Care. 2002;6(4):421-424.

26. Berg G, Nyberg S, Harrison P, Baumchen J, Gurss E, Hennes E. Near-infrared spectroscopy measuremen of sacral tissue oxygen saturation in healthy volun- teers immobilized on rigid spine boards. Prehosp Emerg Care. 2010;14(4):419-424.

27. Lee AY, Elojeimy S, Kanal KM, Gunn ML. The effect of trauma backboards on computed tomography radiation dose. Clin Radiol. 2016. Epub ahead of print.

28. Bauer D, Kowalski R. Effect of spinal immobilization devices on pulmonary function in the healthy, nonsmoking man. Ann Emerg Med. 1988;17(9):915-918.

29. Walsh M, Grant T, Mickey S. Lung function compromised by spinal immobilization. Ann Emerg Med. 1990;19(5):615-616.

30. Totten VY, Sugarman DB. Respiratory effects of spinal immobilization. Prehosp Emerg Care. 1999; 3(4):347-352.

31. Goutcher CM, Lochhead V. Reduction in mouth opening with semi-rigid cervical collars. $\mathrm{Br} J \mathrm{An}$ aesth. 2005;95(3):344-348.

32. Davies G, Deakin C, Wilson A. The effect of a rigid collar on intracranial pressure. Injury. 1996;27(9):647-649.

33. Dunham CM, Brocker BP, Collier BD, Gemmel DJ. Risks associated with magnetic resonance imaging and cervical collar in comatose, blunt trauma patients with negative comprehensive cervical spine computed tomography and no apparent spinal deficit. Crit Care. 2008;12(4):R89.

34. Mobbs RJ, Stoodley MA, Fuller J. Effect of cervical hard collar on intracranial pressure after head injury. ANZ J Surg. 2002;72(6):389-391.

35. Stone MB, Tubridy CM, Curran R. The effect of rigid cervical collars on internal jugular vein dimensions. Acad Emerg Med. 2010;17(1):100-102.

36. Ben-Galim P, Dreiangel N, Mattox KL, Reitman CA, Kalantar SB, Hipp JA. Extrication collars can result in abnormal separation between vertebrae in the presence of a dissociative injury. J Trauma. 2010;69(2):447-450.

37. Podolsky SM, Hoffman JR, Pietrafesa CA. Neurologic complications following immobilization of cervical spine fracture in a patient with ankylosing spondylitis. Ann Emerg Med. 1983;12(9):578-580.

38. Papadopoulos MC, Chakraborty A, Waldron G, Bell BA. Exacerbating cervical spine injury by applying a hard collar. BMJ. 1999;319(7203):171-172.

39. Thumbikat P, Hariharan RP, Ravichandran G, Mcclelland MR, Mathew KM. Spinal cord injury in patients with ankylosing spondylitis: a 10-year review. Spine (Phila Pa 1976). 2007;32(26):2989-2995.

40. Oto B, Corey DJ, Oswald J, Sifford D, Walsh B. Early secondary neurologic deterioration after blunt spinal trauma: a review of the literature. Acad Emerg Med. 2015;22(10):1200-1212

41. Oteir AO, Smith K, Jennings PA, Stoelwinder JU. The prehospital management of suspected spinal cord injury: an update. Prehosp Disaster Med. 2014;29(4):399-402.

42. Hoffman JR, Mower WR, Wolfson AB, Todd KH, Zucker MI. Validity of a set of clinical criteria to rule out injury to the cervical spine in patients with blunt trauma. National Emergency X-Radiography Utilization Study Group. N Engl J Med. 2000;343(2):94-99.

43. Stiell IG, Wells GA, Vandemheen KL, et al. The Canadian $\mathrm{C}$-spine rule for radiography in alert and stable trauma patients. JAMA. 2001;286(15):1841-1848.

44. Stroh G, Braude D. Can an out-of-hospital cervical spine clearance protocol identify all patients with injuries? An argument for selective immobilization. Ann Emerg Med. 2001;37(6):609-615. 